\title{
FICOLOGIA NO CONTEXTO ESCOLAR: ATIVIDADES PRÁTICAS COM ESTUDANTES DO ENSINO MÉDIO DE UMA ESCOLA PÚBLICA DE TERESINA - PI
}

\section{PHYCOLOGY IN SCHOOL CONTEXT: PRACTICAL ACTIVITIES WITH HIGH SCHOOL STUDENTS FROM A PUBLIC SCHOOL OF TERESINA - PI}

\author{
QUADROS, Rogers Stanley da Silva ${ }^{1}$ \\ BATISTA, Maria Gardênia Sousa²
}

\begin{abstract}
RESUMO
O presente artigo tem por objetivo geral apresentar a inserção de discussões sobre Ficologia (estudo das algas), unindo ações realizadas dentro da sala de aula, no campo e laboratório; e como objetivos específicos despertar nos estudantes o interesse pelo estudo da Ficologia; relacionar teoria e prática a partir do estudo das microalgas e desenvolver atividades práticas e a produção de um material didático intitulado "FITOPLÂNCTON: uma gota de conhecimento". Para a efetivação desses objetivos foi utilizado o método de pesquisa e prática tendo como lócus uma Unidade Escolar do Estado do Piauí, localizada no centro da cidade de Teresina e como sujeitos da pesquisa 260 estudantes do Ensino Médio no ano de 2019. A coleta de dados da pesquisa ocorreu em um primeiro momento com a visita ao Parque Lagoas do Norte e no segundo momento, uma aula prática no Laboratório de Ficologia da UESPI, onde os alunos tiveram a oportunidade de visualizar as amostras de microalgas colhidas nas Lagoas do Norte com o uso de microscópio. Em seguida aplicou-se um estudo dirigido junto aos estudantes para avaliar de percepção de conhecimentos sobre a Ficologia. Em conclusão, a pesquisa revelou que a produção de material didático para uso no Ensino Médio como proposta para a promoção do conhecimento, bem como desperta a consciência da responsabilidade ambiental em sala de aula, desenvolvendo um olhar crítico sobre o seu ambiente com a finalidade de assegurar um recurso natural tão necessário e raro em muitas partes do planeta que é a água.
\end{abstract}

PalaVRas ChaVe: Fitoplâncton; Microalgas; Eutrofização; Material Didático; Ensino Médio.

\section{ABSTRACT}

This article aims to present the insertion of discussions about Phycology (algae study), joining actions carried out within the classroom, in the field and laboratory; and as specific objectives

\footnotetext{
1 Mestre no Ensino de Biologia pelo PROFBIO/UESPI/UFMG. Professor do Ensino Fundamental da Prefeitura Municipal de Teresina (PMT) e Ensino Médio da Secretaria de Educação do Piauí (SEDUC-PI). Teresina, PI, Brasil. e-mail: rogersbio@hotmail.com

2 Doutora pela UFRJ/COPPE. Professora adjunta do Curso de Graduação em Ciências Biológicas da Universidade Estadual do Piauí (UESPI). Professora/orientadora PROFBIO/UESPI. Teresina, PI, Brasil. ORCID: https://orcid.org/0000-0001-8281-1277 e-mail: batistamariagardenia@gmail.com.
} 
DOI: $10.12957 /$ e-mosaicos.2020.44907

arouse in students the interest in the study of Phycology; relate theory and practice from the study of microalgae and develop practical activities and the production of a didactic material entitled "Phytoplankton: a drop of knowledge". To achieve these objectives, the research and practice method was used, having as its locus a Piauí State School Unit, located in the center of the city of Teresina, and 260 high school students in the year 2019. The research data collection took place initially with a visit to the Lagoas do Norte Park and, secondly, a practical class at the UESPI Phycology Laboratory, where students had the opportunity to view the microalgae samples collected in the Northern Lagoons using under the microscope. Then, a study was conducted with the students to evaluate the perception of knowledge about the Phycology. In conclusion, the research revealed that the production of teaching material for use in high school as a proposal for the promotion of knowledge, as well as raising awareness of environmental responsibility in the classroom, developing a critical look at its environment with the purpose of ensure a much needed and rare natural resource in many parts of the planet that is water.

KeYwORDS: Phytoplankton; Microalgae; Eutrophication; Courseware; High School.

\section{INTRODUÇÃo}

A fim de facilitar o interesse dos estudantes para uma aprendizagem através de um processo contínuo e de descobertas, a aula não deve ser apenas um processo rotineiro e mecânico. Na procura por uma melhor aprendizagem, a metodologia deve ser variada e apresentar multimodos nas formas de abordar um conteúdo específico. A maneira de se trabalhar um conteúdo possibilita que os alunos tragam seu cotidiano para a sala de aula. Sendo assim, o uso de aulas práticas, em campo e em laboratório constitui-se como uma tentativa de tornar os tópicos mais concretos e interessantes para o ensino, com a finalidade de melhorar a qualidade da aprendizagem (ZOMPERO; LABURÚ, 2010).

Levando-se em conta que o ensino deve se articular às experiências de vida dos indivíduos, os PCN's (2002) enfatizam que as situações de aprendizagem devem se desenvolver a partir das experiências vividas anteriormente pelos sujeitos, na escola ou fora dela, pois elas os levam a construir, mais facilmente, ideias a respeito dos fenômenos científicos.

Quando se relaciona os conteúdos vistos com a situação vivenciada em aulas práticas, temos uma forte tendência em desenvolver no estudante uma sensibilização maior ao mundo natural e cultural, além de propiciar o enriquecimento harmonioso da personalidade do estudante e a aquisição de conhecimentos de conteúdos relacionados à sua vida (RODRIGUES; e OTAVIANO, 2001).

Destacamos que as aulas práticas no ensino das Ciências têm as funções de despertar e manter o interesse dos estudantes, envolvê-los em investigações científicas, desenvolver habilidades e capacidade de resolver problemas e 
DOI: $10.12957 /$ e-mosaicos.2020.44907

compreender conceitos básicos. Essas ideias vão ao encontro do que está nos eixos cognitivos comuns para todas as áreas do conhecimento da matriz de referência do ENEM 2009 (os ENEMs seguintes foram estruturados na mesma matriz de referência de 2009) divulgado pelo MEC. Nessa matriz se destaca a necessidade de desenvolver nos estudantes do Ensino Médio a compreensão de fenômenos, o enfrentamento de situações-problema, a construção de argumentação e a elaboração de propostas (LIMA; e GARCIA, 2011).

Assim, as aulas de laboratório surgem como possibilidades metodológicas mais apropriadas para reduzir a distância entre o conhecimento científico e o senso comum, de forma mais consensual e dinâmica (KRASILCHIK, 2005).

Pode-se perceber, portanto, que as aulas de laboratório são importantes na construção do conhecimento científico, superam o modelo tradicional e asseguram uma relação dinâmica entre o professor e o estudante (PARANÁ, 2008).

Quando um conteúdo apresenta significado, o educando deixa de ser um analfabeto científico, ao desenvolver uma capacidade de leitura, embasada um vocabulário básico de conceitos científicos, podendo se tornar suficiente para perceber a existência de visões contrárias às veiculadas em revistas, jornais e até mesmo em livros didáticos (MARANDINO et al., 2011).

É interessante chamar a atenção de que nas Orientações Curriculares Nacionais para o Ensino Médio existe uma recomendação de que o ensino de Biologia seja pautado na alfabetização científica.

Para Miller (1983, p. 31), a alfabetização científica implica em três dimensões: a) a aquisição de um vocabulário básico de conceitos científicos, b) a compreensão da natureza do método científico e c) a compreensão sobre o impacto da ciência e da tecnologia sobre os indivíduos e a sociedade.

Acreditamos que as aulas práticas de Biologia, tendo em vista o que foi destacado anteriormente, possam contribuir na construção das duas dimensões inicias da alfabetização científica e, consequentemente, abrir caminho para a construção da terceira.

Conforme Chassot, (2003), a alfabetização científica pode ser considerada como uma das dimensões para potencializar alternativas que privilegiam uma educação mais comprometida.

Embora a maioria dos estudantes saiba da existência das microalgas, pouquíssimas experiências com as atividades de aulas teórico-práticas utilizando o microscópio são realizadas para evidenciar esses organismos. Essas atividades são bastante úteis como subsídios a uma maior aprendizagem deste conteúdo em Biologia. Tendo em vista que o conhecimento acerca das algas no Ensino Médio é extremamente fragmentado, acreditamos que pelo fato das algas serem um grupo de organismos 
DOI: $10.12957 / \mathrm{e}-\mathrm{mosaicos} .2020 .44907$

bastante diversificado do ponto de vista ecológico e morfológico, isso pode dificultar o entendimento e a aprendizagem deste conteúdo.

O uso de aulas práticas de Biologia e de material didático-pedagógico no sentido de facilitar o processo de ensino e aprendizagem dos conteúdos de microalgas no ensino médio, poderá promover a prática do conhecimento e discussão das questões trabalhadas, principalmente daquelas relacionadas ao reconhecimento dos grupos e à morfologia das algas. Deste modo, as atividades de caráter teórico prático podem contribuir com a ampliação do interesse dos alunos em relação a determinados conteúdos/conceitos, pois, para além do que é retratado nos livros didáticos, estes terão outras oportunidades de contato e manuseio com os objetos de estudo, permitindo a percepção do real tamanho, da variedade de formas dos organismos estudados dentre outras características, o que contribui de maneira significativa para a criação de novos conhecimentos.

Em relação às microalgas, existe pouca abordagem do conteúdo, especialmente em aulas práticas. Uma das explicações para a pouca utilização do laboratório para este conteúdo pode ser em razão da extensão, que necessita de uma abordagem de muitos grupos de microalgas, e levando à demanda de várias aulas para tratar deste conteúdo.

O uso de atividades práticas pode auxiliar os estudantes no entendimento dos conteúdos de Biologia, especialmente sobre algas. Embora a visualização das microalgas no microscópio possa despertar o interesse nos estudantes, possibilitando um maior contato com o objeto de estudo, a proposta aqui apresentada não é superior a outros métodos didáticos, mas sim um método complementar para uma abordagem mais ampla, citando aspectos ambientais de conservação e proteção às fontes principais de água doce, orientados para o consumo imediato das populações que dependem desse recurso para a sua sobrevivência.

\section{Metodologia}

\section{ATIVIDADES PRÁticas COM ESTUDANTES dO ENSINO MÉdiO DE UMA ESCOLA PÚBLICA DE TERESINA}

Esta pesquisa foi desenvolvida através do estudo do tipo qualitativo com a utilização da metodologia pesquisa-ação. Esta metodologia associa a ação com atividade de pesquisa e pressupõe que os participantes da pesquisa devem ser considerados sujeitos ativos em todo o processo de desenvolvimento da pesquisa. Para isso os participantes foram solicitados e motivados a buscar em conjunto com os pesquisadores soluções para os problemas em estudo (THIOLLENT, 2005). O projeto de pesquisa foi enviado ao Comitê de Ética em Pesquisa, da IES, credenciado no Conselho Nacional de Ética em Pesquisa. 
DOI: $10.12957 /$ e-mosaicos.2020.44907

Este trabalho foi realizado com a colaboração de estudantes e professores do ensino médio de uma Escola Estadual da rede pública do Estado do Piauí. Os estudantes foram selecionados utilizando os seguintes critérios de inclusão: estar cursando o ensino médio no momento da realização da pesquisa e aceitar participar do estudo.

O procedimento adotado para participação na pesquisa foi feito mediante o seguimento das seguintes etapas: solicitação e obtenção da autorização da diretoria da escola para desenvolver a pesquisa com os alunos e professores da Instituição; e entrega dos Termos de Consentimentos Livres Esclarecidos - TCLE para os estudantes e professores que consentiram em colaborar, assinarem o termo, com o devido consentimento para realizar este tipo de colaboração. Neste, estavam explicitados os objetivos da pesquisa e a forma de participação.

A etapa seguinte deu-se com o planejamento da aula em campo com observações para a definição do local a ser estudado, onde optou-se pelo Parque Municipal Lagoas do Norte situado na Zona Norte, área de preservação com acompanhamento de um centro administrativo que disponibilizou técnicos para monitoramento, manutenção e aplicação de informações para os estudantes.

Posteriormente, foi elaborado e enviado à escola um protocolo referente ao projeto, contendo o local da visita, dia/hora, público-alvo, custo da atividade e os responsáveis pela atividade, incluindo-se os professores colaboradores.

A seguinte etapa do projeto deu-se com o desenvolvimento da aula em laboratório. Esta ocorreu no Laboratório de Ficologia da Universidade Estadual do Piauí - UESPI, sob a supervisão da responsável pelo laboratório, junto com os estudantes de graduação em Ciências Biológicas, monitores e estagiários do referido laboratório. Nessa etapa, foi realizada uma atividade de observação do material coletado, com a confecção e posterior análise no microscópio óptico, seguindo as técnicas usuais em ficologia (BICUDO et al, 2006). Nessa ocasião os estudantes e professores puderam vislumbrar microalgas presentes na água, fotografar e reconhecer sua classificação. Além do material coletado foram também apresentadas outras lâminas confeccionadas para melhor demonstração das algas que constituem o fitoplâncton.

\section{Aula em Campo - Parque lagoas do Norte - Teresina - Piauí}

Foram conduzidos ao Parque das Lagoas do Norte, 260 estudantes, distribuídos em três turmas de $1^{\circ}$ ano, duas turmas de $2^{\circ}$ ano e duas turmas de $3^{\circ}$ ano do Ensino Médio. Ao chegarem ao parque, os alunos foram recepcionados pela equipe técnica do parque e receberam folhetos informativos sobre o Parque Lagoas do Norte para compreenderem a organização, a constituição faunística e florística do ambiente, e os 
DOI: $10.12957 /$ e-mosaicos.2020.44907

projetos desenvolvidos através de investimentos oriundos do Banco Mundial, segundo informações dadas pelos técnicos ambientais do Parque.

Ao iniciar a trilha, os estudantes foram orientados quanto ao percurso e as observações a serem feitas contidas no roteiro da aula que foi entregue para cada dupla de estudantes. O roteiro serviu de auxílio para o desenvolvimento da aula em campo, destacando o objetivo em despertar no estudante o interesse pela investigação em relação às algas. Foram abordados alguns termos tais como eutrofização e ações antrópicas que seriam responsáveis em causar alterações no ambiente aquático envolvendo também as cianobactérias. Durante esta aula de campo, foi ensinada a metodologia de coleta de amostras de água para a observação de microalgas no microscópio óptico.

Fig. A

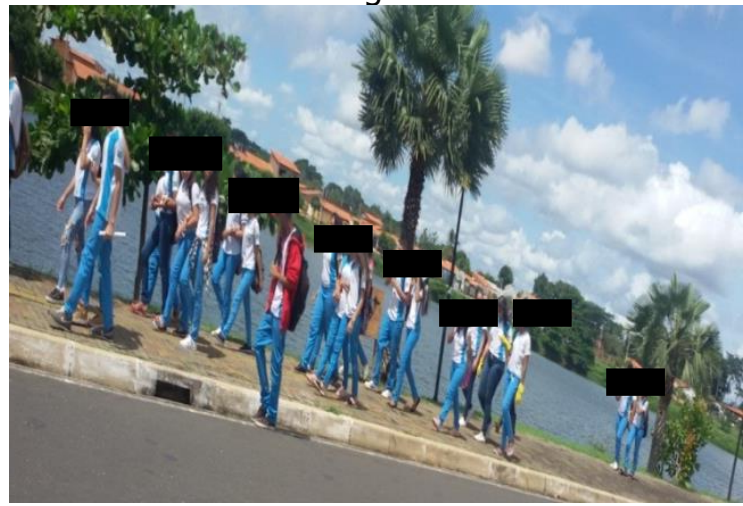

Pesquisa direta, 2019. Atividades dos alunos em campo - Parque Lagoas do Norte - Teresina - PI.
Fig. B

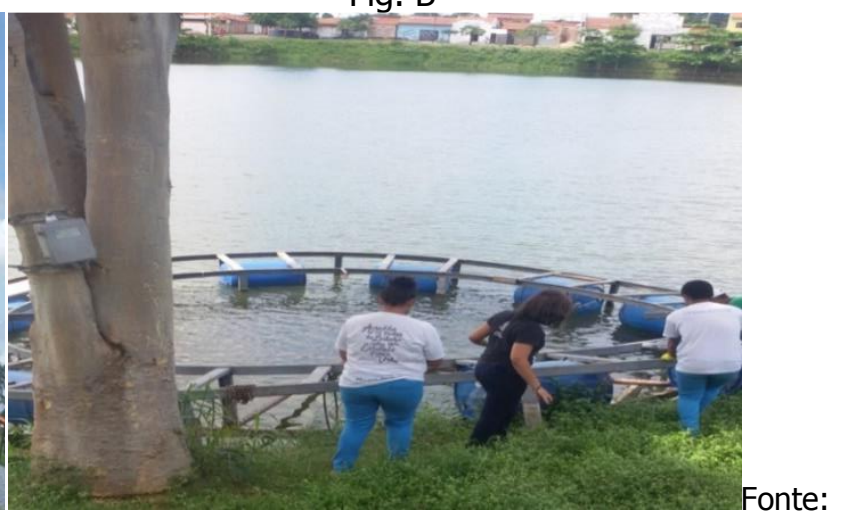

onte:

\section{AULA No Laboratório de Ficologia na Universidade Estadual do PiaUí - TERESINA - PI}

Os estudantes foram orientados quanto as normas e condutas em laboratório, seguindo o roteiro de aula prática sobre observação de microalgas. Utilizando microscópios ópticos, os alunos tiveram a oportunidade de visualizar nas amostras das águas coletadas do Parque Lagoas do Norte, a ocorrência da diversidade de algas fitoplanctônicas, incluindo cianobactérias.

Nesta etapa, no laboratório de Ficologia da UESPI, os alunos apresentaram entusiasmo com as observações realizadas em microscopia óptica. Assim como, com exposição dialogada sobre as observações feitas, destacando a identificação, classificação e características das microalgas observadas. Os alunos também fotografaram as imagens das algas ao microscópio com celulares e ao final, elaboraram relatórios para discussão e avaliação em sala de aula. Foi solicitado aos estudantes, no final do desenvolvimento das atividades, a elaboração de um depoimento no qual 
DOI: $10.12957 /$ e-mosaicos.2020.44907

deveriam incluir sua opinião sobre a aplicação das atividades em campo e em laboratório.

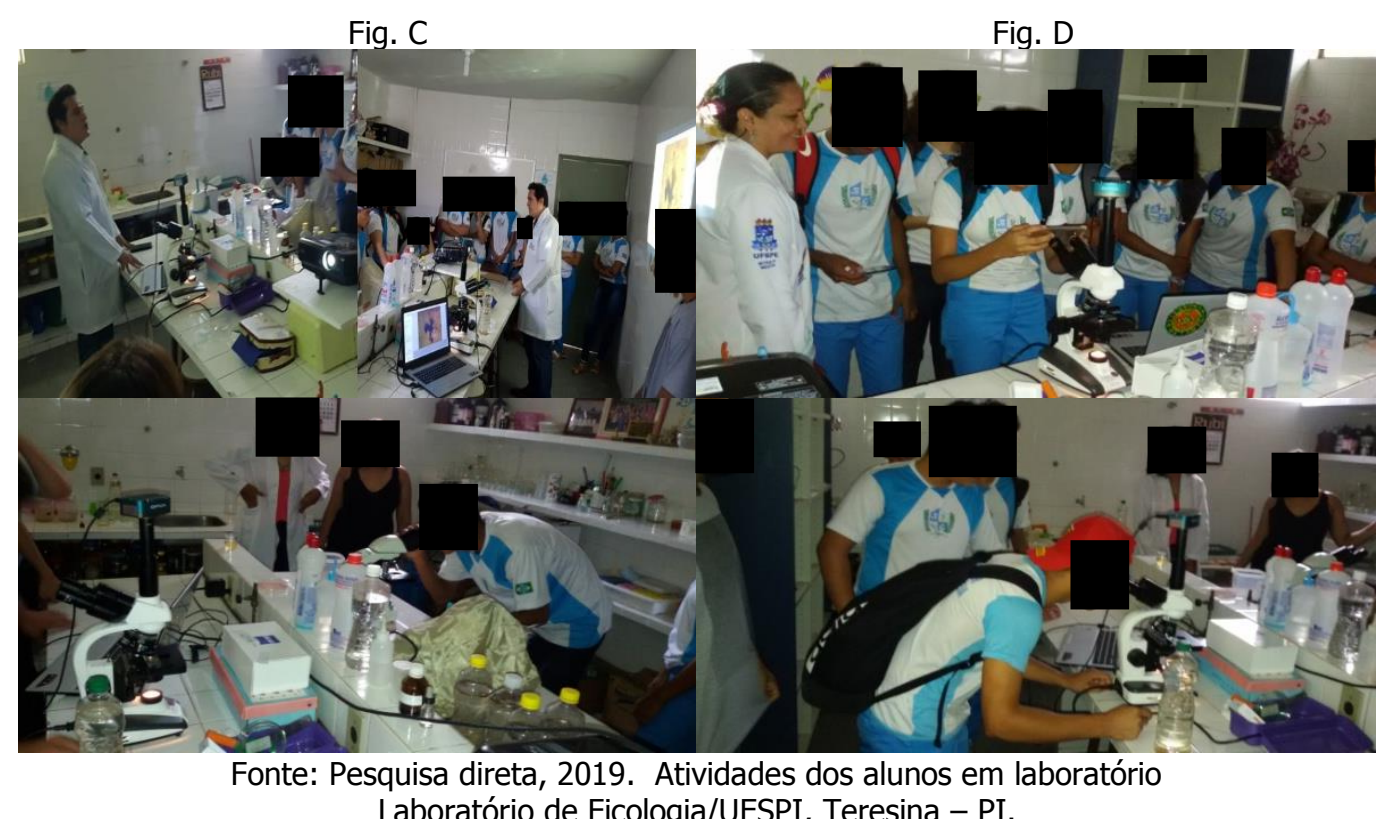

Laboratório de Ficologia/UESPI, Teresina - PI.

\section{Depoimento dos estudantes de uma escola Pública de Teresina - Pi sobre APLICAÇÃO DE ATIVIDADES PRÁTICAS (EM CAMPO E NO LABORATÓRIO) SOBRE FICOLOGIA}

Dentre todos os depoimentos coletados, alguns foram destacados neste artigo. A opinião dos estudantes diz respeito à aplicação das aulas em campo e no laboratório sobre Ficologia, a fim de analisar o entendimento em relação ao conteúdo de Ficologia abordado no contexto escolar no Ensino Médio numa Escola Estadual, em Teresina, Piauí.

"Duas aulas realizadas fora da escola que além de experiência ganhamos conhecimento, no Parque Lagoas do Norte, conhecemos a Lagoa do Lourival e Lagoa dos Orixás. Coletamos água das Lagoas e visualizamos no microscópio no Laboratório de Ficologia da UESPI, estudando as várias espécies de microalgas, e com essas aulas, adquirimos aprendizado e experiência". (estudante 1)

No contexto escolar, ensinar e aprender exige hoje muito mais flexibilidade, espaço temporal e pessoal e de grupo, menos conteúdos fixos e processos mais abertos de pesquisa e comunicação. Temos hoje muitas informações e dificuldades em escolher quais são significativas para nós e integrá-las dentro da nossa mente e da 
DOI: $10.12957 / \mathrm{e}-\mathrm{mosaicos} .2020 .44907$

nossa vida. Com o incremento das novas tecnologias, faz-se necessário que o professor incorpore processos participativos e compartilhamento de ensino e aprendizagem por meio de uma comunicação mais aberta, confiante, de motivação constante, de integração de todas as possibilidades teórico-práticas visando a um processo dinâmico e amplo de informação inovadora promovendo a integração do objeto de estudo em todas as dimensões: cognitivas, emotivas, sociais, éticas, levando o aluno a compreender melhor as áreas específicas do conhecimento.

"Aprendemos muitas coisas sobre as lagoas e foi muito bom! No meu ponto de vista, essa aula em campo é melhor que está em sala de aula; e no laboratório foi possível aprofundar mais no nosso aprendizado". (estudante 2)

"Eu gostei muito e gostei porque nós fomos para a Lagoa do Norte e vimos os animais na lagoa: o jacaré, e os cágados e os pássaros. Lá falaram da contaminação da Lagoa e que as pessoas correm risco de dengue, ali ao lado da lagoa do Norte. E lá no laboratório da UESPI, nós vimos as microalgas que também encontramos na Lagoa do Norte". (estudante 3)

Continuamente, a sociedade está mudando nas suas formas de organizar-se, e em especial de ensinar e de aprender. Havendo uma necessidade urgente em incrementar as metodologias, para ajudar os alunos a compreenderem áreas específicas do conhecimento. Ensinar é um processo social profundamente pessoal. Cada um de nós desenvolve um estilo, caminho dentro do que está previsto. Ensinar depende também de o aluno querer e estar apto com um nível de maturidade, motivação e competência adquirida (MORAN, 2001).

"Eu achei muito bom. Os professores nos levaram a Lagoa para coletar água. Os professores explicaram sobre as lagoas, os tipos de animais e depois nós fomos para a UESPI estudar as microalgas das águas que recolhemos. Eles explicaram tudo sobre microalgas. Também vimos microscópio, vimos que nessas águas, há muitos riscos ao tomar banho podendo causar coceiras na pele. Achei muito bom, porque na prática nós aprendemos muito mais". (estudante 4)

"As aulas passeio são muito importantes, além disso, são até melhores para alguns alunos que têm dificuldades de aprender em sala de aula. O Parque Lagoas do Norte é um lugar muito bom pra se contemplar, há animais, pássaros e plantas, tudo muito lindo. O laboratório de Ficologia da UESPI trouxe boa experiência para os alunos. Tudo muito organizado". (estudante 5) 
DOI: $10.12957 /$ e-mosaicos.2020.44907

O ensino é um processo onde o professor deve estimular o aluno através de estímulos exteriores, incluindo entre estes as instruções verbais do professor. Para Freire (1998, p.25) "ensinar não é transferir conhecimentos, mas criar as possibilidades para a sua produção ou a sua construção".

Ensinar, na perspectiva de transmitir conhecimentos, somente tem um sentido em um ambiente imutável, tal como o de uma sociedade primitiva, tradicional ou estagnada. No ambiente de hoje, a concepção deve facilitar a mudança e a aprendizagem (BORDENAVE \& PEREIRA, 2001).

Assim, a criação de mecanismos para a facilitação da aprendizagem deve ter a preocupação de como, porque e quando aprendem os alunos, como se vive e se sente a aprendizagem, e quais as suas implicações em seu cotidiano.

\begin{abstract}
"Foi uma ótima oportunidade, pois com a aula prática, tivemos a oportunidade de nos aproximar mais desse universo da Biologia, especialmente do estudo de algas e microalgas. No Parque Lagoas do Norte, tivemos a oportunidade de coletar a água de uma das Lagoas e em seguida, examiná-la do microscópio, pudemos ver as microalgas e separá-las por espécies. Após a coleta e análise chegamos à conclusão que a água é imprópria para o consumo". (estudante 6)
\end{abstract}

Entretanto, Behrens (2001) comenta que, o advento da economia globalizada e a forte influência dos avanços dos meios de comunicação e dos recursos de informática aliados à mudança de paradigma da ciência não comportam um ensino que se caracterize por uma prática pedagógica conservadora, repetitiva e acrítica.

É importante que a aprendizagem seja entendida como uma mudança de comportamento provocada pela experiência do outro ser humano e não meramente pela experiência própria e prática em si, ou pela repetição ou associação automática de estímulos e respostas.

Fonseca (1998) enfatiza que a aprendizagem humana é possível pela ação de um mediatizador que se interpõe entre os estímulos e o organismo para captar da mente do mediatizado as significações que advêm da própria experiência de aprendizagem para provocar nele estados de alerta, de processamento, de planificação e de transcendência, mudanças e arranjos de informação, modulando o tempo, 0 espaço e a intensidade dos estímulos, humanizando-os e conferindo-Ihes significação, como instrumentos psicológicos mais aptos e flexíveis para produzirem soluções às situações problemas 'provocadas' pela natureza e pela cultura.

"A aula no Parque Lagoas do Norte, foi incrível, uma experiência nova, um novo conhecimento sobre a fauna e a flora do Parque. A aula no 
DOI: $10.12957 /$ e-mosaicos.2020.44907

Laboratório de Ficologia da UESPI nos ensinou que existem algas presentes nas águas que foram retiradas de uma das Lagoas, algas que podem até matar!" (estudante 7)

As mudanças de paradigmas em todas as instituições de ensino exigem da população uma aprendizagem constante. Portanto, as pessoas precisam estar preparadas para aprender ao longo da vida podendo intervir, adaptar-se e criar novos cenários. Isto corrobora com Behrens (2001) ao dizer que as exigências de uma economia globalizada afetam diretamente a formação dos profissionais em todas as áreas. Torna-se relevante alertar que o profissional esperado para atuar na sociedade contemporânea exige hoje uma formação qualitativa diferenciada do que se tem ofertado em um grande número de universidades.

Assim o professor deve assumir o papel de preparar os estudantes para um processo de educação continuada que deverá acompanhá-lo durante toda a vida. 0 universo de informações ampliou-se muito nos últimos tempos com isso, o contexto escolar tem buscado a adoção de nova abordagem, de modo a ensejar a capacidade de investigação e a de aprender a aprender.

"Meu conhecimento sobre algas, especialmente sobre o fitoplâncton melhorou muito com as aulas práticas em campo e no laboratório". (estudante 9)

"Eu achei muito legal, pois aprendi, muitas coisas como coletar água e ver algas no microscópio e vimos que a Lagoa tem várias coisas e isso pode provocar danos em nossos corpos. E achei incrível é que em uma gota de água dá pra ver coisas como várias espécies de algas". (estudante 8)

Quando utilizamos metodologias diferenciadas em sala de aula, os conceitos são transmitidos através de canais que potencializam a capacidade de transmissão e facilitam a possibilidade de recuperação da informação (TAVARES, 2004). Para estimular o modo representacional, as experiências devem ser observadas de forma imperativa para o ensino das Ciências, não apenas retratando a natureza epistemológica do conhecimento científico, mas carregando uma característica pedagógica que em combinação com outros modos e formas representacionais, complementam e aprimoraram a formação do pensamento científico. Portanto, as aulas práticas, em campo e no laboratório, são formas sinestésicas de representação, pois a Ciência não fala apenas do mundo na linguagem das palavras, e em muitos casos, simplesmente não pode fazê-lo. A linguagem natural da Ciência é uma integração sinérgica de palavras, com diferentes linguagens para ensinar, 
DOI: $10.12957 /$ e-mosaicos.2020.44907

especialmente de forma prática, vivenciada, observada e materializada (LABURÚ \& SILVA, 2011). Segundo a teoria Freire (1997) torna-se necessário experienciá-la.

Deste modo, a realização de experimentos (aulas práticas), representa um excelente mecanismo para que o aluno relacione a teoria à prática.

\section{CONSIDERAÇõES FinAIS}

A presente pesquisa se propôs a aplicar o método da investigação com o uso de atividades práticas em campo e no laboratório como estratégia didática para facilitar a aprendizagem significativa de estudantes do ensino médio referente ao contexto de Ficologia. Consideramos que a utilização de aulas práticas e em campo são representações para aprendizagem significativa, especialmente no contexto de algas microscópicas.

Além disso, essa estratégia aumenta o interesse do estudante nos conteúdos abordados em sala de aula, ou seja, aulas interativas com campo e práticas em laboratório que abordam os conteúdos botânicos, especialmente referidos aqui em Ficologia no contexto das microalgas planctônicas. Essa interação torna os conteúdos mais atraentes e interessantes, viabilizando a aprendizagem significativa, pois há uma relação do assunto apreendido em sala de aula com o seu dia a dia, facilitando a construção de novos significados.

Foi verificado que os estudantes participantes da pesquisa já possuíam conhecimentos prévios em sua estrutura cognitiva. Esses conhecimentos prévios são significativos para os alunos, pois são aprendidos sob seu contexto familiar, escolar e cultural. Após as aulas ocorreu uma reorganização cognitiva do conteúdo.

Pôde-se observar ainda, que também ocorrem incoerências no contexto de algas ainda pouco explorado no ensino médio, como a falta de conceitos, definições de termos e uma desordem no conhecimento da hierarquização e da classificação sistemática no que se refere às algas.

Com o desenvolvimento das atividades, verificou-se que os alunos sentiram-se mais estimulados com as atividades propostas pelo professor, cumprindo todas as etapas exigidas pelos dois momentos: as aulas passeio e a visita ao laboratório de Ficologia, alcançando os principais objetivos que traziam como etapas: a pesquisa e a ação. A maioria dos estudantes colocou-se à disposição para participar, redigindo os pareceres das aulas passeio e da análise do material didático, o livro sobre Ficologia, construído após todos os momentos aplicados, sabendo que seria parte de uma terceira avaliação correspondente ao período letivo de 2019.

Observou-se que, em ambientes não formais como o Parque Ambiental Lagoas do Norte e o Laboratório de Ficologia da UESPI servem como incentivos para o 
DOI: $10.12957 /$ e-mosaicos.2020.44907

enriquecimento das aulas, despertando nos alunos, um espírito de investigação do saber proposto pelo professor, com grande ênfase na construção de atitudes responsáveis que os tornam capazes de modificar, conservar o espaço onde vivem e perpetuar as suas ações com a postura adquirida, exaltando o respeito ao meio ambiente com perspectiva de conservar os recursos hídricos, não somente para si, mas também para as futuras gerações.

E, por fim, destacamos a ideia de que os professores tendem a reproduzir na sua prática profissional muitas das experiências que tiveram enquanto alunos, sendo assim, deve-se incrementar os cursos de formação inicial e continuada, que possam apresentar ao docente um leque de possibilidades conceituais e metodológicas de ensino-aprendizagem para o preparo de suas aulas. "Para que o professor possa melhorar suas competências profissionais e metodologias de ensino, além da própria reflexão e atualização sobre o conteúdo da matéria ensinada e os recursos metodológicos a serem utilizados, precisa estar em estado permanente de aprendizagem". (KENSKI,2003, p.18)

Por fim, destacamos a ideia de que os professores tendem a reproduzir na sua prática profissional muitas experiências que tiveram enquanto alunos, sendo assim, deve-se incrementar os cursos de formação inicial e continuada, que possam apresentar ao docente um leque de possibilidades conceituais e metodológicas de ensino-aprendizagem para o preparo de suas aulas.

\section{AgRADECIMENTOS}

Ao PROFBIO, à CAPPES, à UESPI, ao Laboratório de Ficologia da Universidade Estadual do Piauí (UESPI) e a uma das escolas estaduais do Estado do Piauí, Escola Barão de Gurgueia, pelo uso das instalações, realização das aulas e coleta de dados.

\section{REFERÊNCIAS}

BEHRENS, M. Pacto: Aprendizagem colaborativa com. tecnologia interativa. Curitiba: PUCPR: CDROM, 2001.

BICUDO, C. E. M.; MENEZES, M. Gêneros de algas continentais do Brasil: chave para identificação e construções. São Carlos: Rima, 2006.

BORDENAVE, J. D.; PEREIRA, A. M. Estratégias de ensino-aprendizagem. 22.ed. Petrópolis: Vozes, 2001. 
DOI: $10.12957 /$ e-mosaicos.2020.44907

BRASIL. Parâmetros Curriculares Nacionais: terceiro e quarto ciclos do ensino fundamental: Ciências Naturais. Brasília: MEC/SEF, 2002.

CHASSOT, A. Alfabetização científica: uma possibilidade para a inclusão social. Revista Brasileira de Educação, n. 22, p. 89-100, 2003.

FREIRE, P. Pedagogia da autonomia. Rio de Janeiro, Editora Paz e Terra, 1997.

FREIRE, P. Pedagogia da autonomia: saberes necessários à prática educativa. 7. ed. Rio de Janeiro: Paz e Terra, 1998.

FONSECA, V. da. Psicomotricidade: filogênese, ontogênese e retrogênese. Porto Alegre: Artes Médicas, 1998.

KENSKI, Vani M. Educação E Tecnologias - O Novo Ritmo Da Informação. São Paulo: Papirus, 2003.

KRASILCHIK, M. Prática de ensino de Biologia. São Paulo: Editora da Universidade de São Paulo, 2004.

LABURÚ, C. E. \& SILVA, O. H. M. Multimodos e múltiplas representações:

fundamentos e perspectivas semióticas para a aprendizagem de conceitos científicos. Investigações em Ensino de Ciências 16: 7-33, 2011.

LIMA, D. B. de; GARCIA, R. N. Uma investigação sobre a importância das aulas práticas de Biologia no Ensino Médio. 2011. Disponível em:

https://seer.ufrgs.br/CadernosdoAplicacao/article/viewFile/22262/18278. Acesso em: 20 mar. 2019.

MARANDINO, M. et al. Ensino de Biologia: histórias e práticas em diferentes espaços educativos. São Paulo: Cortez, 2009.

MILLER, J. D. Scientific literacy: a conceptual and empirical review. Daedalus, v. 112, n. 2, p. 29-48, 1983.

Ministério da Educação (MEC), Secretaria de Educação Média e Tecnológica (Semtec). PCN + Ensino médio: orientações educacionais complementares aos Parâmetros Curriculares Nacionais - Ciências da Natureza, Matemática e suas Tecnologias. Brasília: MEC/Semtec, 2002.

MORAN, J. M. Novas Tecnologias e Mediação Pedagógica. Campinas: Papirus, 2001. 
DOI: $10.12957 / \mathrm{e}-\mathrm{mosaicos} .2020 .44907$

PARANÁ. Secretaria de Estado da Educação. Diretrizes Curriculares de Educação Física para os anos finais do Ensino Fundamental e para o Ensino Médio. Curitiba: SEED, 2008.

RODRIGUES, A.B.; OTAVIANO, C. Guia Metodológico de Trabalho de Campo em Geografia. Revista Geografia, Londrina, n.1, v.10, p. 35-43, jan./jun. 2001.

THIOLLENT, M. Metodologia da Pesquisa-ação. 14. ed. São Paulo: Editora Cortez, 2005.

TAVARES, R. Aprendizagem Significativa. Revista Conceitos, n.55, 2004.

ZOMPERO, A. F.; LABURU, C. E. Atividades investigativas no ensino de ciências: aspectos históricos e diferentes abordagens. Ensaio: pesquisa em educação em ciências, Belo Horizonte, v. 13, n. 3, p. 67-80, 2011.

Recebido em 29 de agosto de 2019

Aceito em 30 de outubro de 2019

A e-Mosaicos Revista Multidisciplinar de Ensino, Pesquisa, Extensão e Cultura do Instituto de Aplicação Fernando Rodrigues da Silveira (CAp-UERJ) está licenciada com uma Licença Creative Commons - Atribuição-NãoComercial 4.0 Internacional.

Os direitos autorais de todos os trabalhos publicados na revista pertencem ao(s) seu(s) autor(es) e coautor(es), com o direito de primeira publicação cedido à e-Mosaicos.

Os artigos publicados são de acesso público, de uso gratuito, com atribuição de autoria obrigatória, para aplicações de finalidade educacional e não-comercial, de acordo com o modelo de licenciamento Creative Commons adotado pela revista. 